\title{
Erratum to: Evaluating interactions between the heavy forging process and the assisting manipulator combining FEM simulation and kinematics analysis
}

\author{
Wu-rong Wang $\cdot$ Kai Zhao $\cdot$ Zhong-qin Lin $\cdot$ Hao Wang
}

Published online: 2 March 2010

(C) Springer-Verlag London Limited 2010

Erratum to: Int J Adv Manuf Technol

DOI 10.1007/s00170-009-2285-3

Unfortunately, an error occurred in the author affiliations.

The correct affiliations are given below.

W. Wang $(*)$ :

School of Materials Science and Engineering,

Shanghai University,

Room 202, Metal Building, No. 149 Yanchang Road,

Shanghai 200072, China

e-mail: wangwurong_1979@hotmail.com

The online version of the original article can be found at http://dx.doi. org/10.1007/s00170-009-2285-3.

W.-r. Wang $(\bowtie)$

School of Materials Science and Engineering, Shanghai

University,

Room 202, Metal Building, No. 149 Yanchang Road,

Shanghai 200072, China

e-mail: wangwurong_1979@hotmail.com

K. Zhao $\cdot$ Z.-q. Lin $\cdot$ H. Wang

State Key Laboratory of Mechanical System and Vibration,

Shanghai JiaoTong University,

Shanghai 200240, China 